\title{
Serotonergic and Noradrenergic Markers of Post-Traumatic Stress Disorder with and without Major Depression
}

\author{
Michael Maes, M.D., Ph.D., Ai-hua Lin, M.D., M.Sci., Robert Verkerk, Ing., Laure Delmeire, M.D., \\ An Van Gastel, M.D., Marc Van der Planken, M.D., Ph.D., and Simon Scharpé, Ph.D.
}

\begin{abstract}
Some studies have suggested that disorders in the peripheral and central metabolism of serotonin (5-HT) and noradrenaline (NE) may play roles in the pathophysiology of post-traumatic stress disorder (PTSD). This study examines (1) the availability of plasma total tryptophan, the precursor of 5-HT, and tyrosine, the precursor of NE; and (2) the platelet 5-HT transporter and $\alpha 2$-adrenoceptor $(\alpha 2-A R)$ binding sites in patients with PTSD and healthy volunteers. High-performance liquid chromatography (HPLC) was employed to measure plasma tryptophan and tyrosine as well as amino acids known to compete with the same cerebral transport system; that is, valine, leucine, phenylalanine, and isoleucine. The maximum number of binding sites $\left(B_{\max }\right)$ and their affinity $(K d)$ for binding to $\left[{ }^{3} \mathrm{H}\right]$-paroxetine and $\left[{ }^{3} \mathrm{H}\right]$-rauwolscine, a selective $\alpha 2-A R$ antagonist, were determined. $\left[{ }^{3} \mathrm{H}\right]$-paroxetine and $\left[{ }^{3} \mathrm{H}\right]$-rauwolscine binding Kd values were significantly higher in patients with PTSD than in healthy volunteers. $\left[{ }^{3} \mathrm{H}\right]$-rauwolscine binding $\mathrm{Kd}$ values were significantly higher in patients with PTSD and concurrent major
\end{abstract}

depression (MD) than in PTSD patients without MD and healthy volunteers. Plasma tyrosine concentrations and the ratio of tyrosine/valine + leucine + isoleucine + phenylalanine + tryptophan were significantly higher in PTSD patients with MD than in those without MD and healthy volunteers. The results show that PTSD is accompanied by lower affinity of paroxetine binding sites and that PTSD with concurrent MD is accompanied by lower affinity of $\alpha 2$-ARs and increased plasma tyrosine availability to the brain. The results suggest that (1) serotonergic mechanisms, such as defects in the 5-HT transporter system, may play a role in the pathophysiology of PTSD; and (2) that catecholaminergic mechanisms, such as increased precursor availability and lowered affinity of $\alpha 2-A R s$, may play a role in the pathophysiology of PTSD with concurrent MD. [Neuropsychopharmacology 20: 188-197, 1999] (C) 1998 American College of Neuropsychopharmacology. Published by Elsevier Science Inc.
KEY WORDS: Post-traumatic stress disorder; Depression; Serotonin; Norepinephrine; Tryptophan; Tyrosine

From the Clinical Research Center for Mental Health [CRC-MH] (MM, A-hL, LD), Antwerp, Belgium; Department of Psychiatry (MM), Vanderbilt University, Nashville, Tennessee, USA; IRCSS (MM), Fatebenefratelli, Brescia, Italy; Department of Medical Biochemistry (RV, SS), University of Antwerp, Wilrijk; and Department of Hematology (MVDP), University Hospital of Antwerp, Antwerp, Belgium.

Address correspondence to: Michael Maes, M.D., Ph.D., Director Clinical Research Center for Mental Health (CRC-MH), University Department of Psychiatry, AZ Stuivenberg,Lange Beeldekensstraat 267, 2060 Antwerpen, Belgium.

Received 11 November 1997; revised 21 April 1998; accepted 29 April 1998.
Post-traumatic stress disorder (PTSD) is an anxiety disorder that may occur after exposure to extreme traumatic events, such as natural disasters (e.g., flood), accidental (e.g., car accidents, fire), and deliberate manmade (e.g., war camps, torture, wars) traumatic events (APA 1980; 1987; 1994). The core symptoms and diagnostic criteria according to the DSM (III, III-R, and IV) are reexperiencing the trauma; numbing of responsiveness and avoidance; and hyperarousal. The condition is highly prevalent, with considerable morbidity and a high co-morbidity with other psychiatric disorders, such as major depression (APA 1980; 1987; 1994). 
Recent research on the biological pathophysiology of PTSD has found some evidence for roles of catecholamines and serotonin (5-HT). Findings on increased catecholaminergic or sympathetic nervous system (SNS) activity in PTSD are fairly consistent across studies. First, combat veterans with PTSD show significantly higher 24-h urinary excretion and plasma concentrations of catecholamines, such as noradrenaline (NE), adrenaline, and dopamine, than normal controls, other psychiatric patients, or combat veterans without PTSD (Kosten et al. 1987; Mason et al. 1988; Yehuda et al. 1992; Hammer and Diamond 1993; Lemieux and Coe 1995; Yatham et al. 1996). Second, combat veterans show a significantly higher rise than normal volunteers in plasma NE and peripheral SNS activity following acute laboratory stressors with stimuli reminiscent of the trauma (Blanchard et al. 1991; Krystal et al. 1989). Third, PTSD patients have significantly decreased platelet $\left[{ }^{3} \mathrm{H}\right]$-rauwolscine binding $B_{\max }$ values, suggesting a downregulation of $\alpha 2$-adrenoceptors ( $\alpha 2$-ARs) on platelets (Perry et al. 1987). Fourth, challenge with yohimbine, an $\alpha 2-\mathrm{AR}$ antagonist that preferentially blocks the presynaptic $\alpha 2-\mathrm{AR}$ autoreceptor (Starke et al. 1975), resulted in significantly higher plasma levels of 3-methoxy-4-hydroxyphenylglycol (MHPG), the major NE metabolite, in PTSD veterans than in control subjects (Southwick et al. 1993). These results suggest that central presynaptic $\alpha 2$-ARs are subsensitive in PTSD (Southwick et al. 1993). No significant alterations in 24-h urinary NE excretion and lower arterialized plasma NE concentrations have been found by other authors (Pitman and Orr 1990; Mellman et al. 1995; Murburg et al. 1995). However, to the best of our knowledge, no research has examined plasma tyrosine, the precursor of NE, in PTSD. There is evidence that the rate of formation of brain NE is determined by brain tyrosine concentrations, which are reflected in the plasma by the molar ratio of tyrosine to other amino acids known to compete for the same cerebral uptake site; that is, the competing amino acids (CAA) tryptophan, phenylalanine, leucine, isoleucine, and valine (reviews: Moller 1986a; Salter and Pogson 1987; Voog and Eriksson 1992). During stressful events, an increase in plasma tyrosine and the tyrosine/CAA is observed; whereas, the increased tyrosine/CAA ratio is related to increased brain noradrenergic turnover (review: Rao 1987).

Supportive findings that alternations in serotonergic metabolism may play roles in the pathophysiology of PTSD include the following. First, selective 5-HT reuptake inhibitors (SSRIs), such as fluoxetine, have beneficial effects in the treatment of PTSD (van der Kolk et al. 1994). Second, platelet $\left[{ }^{3} \mathrm{H}\right]$-paroxetine binding $B_{\max }$ and $\mathrm{Kd}$ values were significantly lower in PTSD patients than in normal controls, suggesting a lower number of platelet 5-HT transporters in PTSD patients (Arora et al. 1993). The 5-HT transporter plays a critical role in 5-HT neurotransmission by reclaiming synaptic 5-HT. Arora et al. (1993) have argued that platelet $\left[{ }^{3} \mathrm{H}\right]$-paroxetine binding may reflect 5 -HT transporter activity. Third, maximal responders to subchronic treatment with fluoxetine had significantly lower pretreatment platelet $\left[{ }^{3} \mathrm{H}\right]$-paroxetine binding $\mathrm{Kd}$ values than partial responders, suggesting that lower $\mathrm{Kd}$ values are possible predictors of SSRI response in PTSD (Fichtner et al. 1994). However, whether PTSD is accompanied by lower availability of plasma total tryptophan, the precursor of 5-HT, remains elusive. Total plasma tryptophan as well as the tryptophan/CAA ratio are indicators for the availability of tryptophan to the brain (Fernstrom 1984) and, hence, for 5-HT synthesis in the brain (Moir and Eccleston 1968). Lowered plasma tryptophan availability is thought to play a role in the serotonergic pathophysiology of major depression (Maes and Meltzer 1995).

The aims of the present study were to examine whether PTSD with or without co-morbid major depression is accompanied by (1) serotonergic disorders, such as lowered platelet $\left[{ }^{3} \mathrm{H}\right]$-paroxetine binding $\mathrm{B}_{\max }$ values, increased $\left[{ }^{3} \mathrm{H}\right]$-paroxetine binding $\mathrm{Kd}$ values, and lower plasma tryptophan concentrations; and (2) noradrenergic disorders, such as lowered platelet $\left[{ }^{3} \mathrm{H}\right]$-rauwolscine binding $\mathrm{B}_{\max }$ values, increased $\left[{ }^{3} \mathrm{H}\right]$-rauwolscine binding $\mathrm{Kd}$ values, and increased plasma tyrosine concentrations.

\section{SUBJECTS}

In the present study, 57 subjects participated. In study group 1, we examined the plasma amino acids in 32 normal volunteers and 13 outpatients with PTSD. In study group 2 , we examined platelet $\left[{ }^{3} \mathrm{H}\right]$-paroxetine and $\left[{ }^{3} \mathrm{H}\right]$-rauwolscine binding characteristics in 12 normal volunteers and 12 of the above patients with PTSD. The patients were victims of two accidental man-made traumatic events that occurred in Vlaanderen (i.e., a December 31, 1994 fire in an Antwerp hotel and a February 27, 1996 multiple collision, car crash, Deinze). The patients developed PTSD 9 months after the traumatic event. We employed the Composite International Diagnostic Interview (CIDI), PTSD Module, to make the diagnosis of PTSD according to the DSM-III-R criteria (Janca et al. 1994; Peters et al. 1996). The CIDI-PTSD module, is a structured diagnostic interview that covers all DSM-III-R (APA 1987) criteria for PTSD. Because we were unable to validate the DSM-III-R diagnostic criteria for PTSD in factor and cluster analytic studies performed on 185 victims from the above traumatic events, we reclassified the patients according to results of cluster analysis, which divided the 185 victims in cases and noncases (Maes et al. 1998a; 1998b). This cluster analyti- 
cally derived classification was less conservative than that of the DSM-III-R. Of the 13 PTSD patients included here, nine had PTSD according to DSM-III-R criteria, and four patients were classified as being PTSD cases according to the cluster analysis.

Normal volunteers and PTSD patients had the usual blood tests (serum electrolytes, urea), liver function tests ( $\gamma \mathrm{GT}$, SGPT, SGOT), and thyroid function tests (FT4 and basal thyroid secreting hormone). All subjects were free of any infections, and inflammatory or allergic reactions for at least 2 weeks before blood samplings. Exclusion criteria for PTSD patients and healthy volunteers were: subjects suffering from a neurological, inflammatory, endocrine or clinically significant chronic disease; immunocompromised subjects; subjects receiving drugs with known or potential interaction with plasma amino-acids, 5-HT and $\alpha 2$-ARs, and immune and endocrine functions. All healthy volunteers had a negative past, present, or family history for psychiatric disorders. None was a regular drinker and none had ever taken psychotropic drugs. All were free of any medications for at least 1 month.

Exclusion criteria for PTSD patients were a present or past history of other axis-I diagnoses, such as bipolar, schizophrenic, paranoid, organic mental, psychoactive substance use and eating disorders. Patients who had suffered from major depression before the traumatic event were also excluded. However, PTSD patients who developed major depression within 9 months after the trauma were included in the present study. Axis-I diagnoses were made according to DSM-III-R criteria (APA 1987), using the Structured Interview for the DSM-III-R, patient version (Spitzer et al. 1990). Severity of depression was measured by means of the Hamilton Depression Rating Scale (HDRS, Hamilton 1960). All PTSD patients with or without major depression were free of any psychotropic drugs and substance abuse since the traumatic event.

\section{METHODS}

Blood collections and clinical assessments were carried out 7-9 months after the traumatic event. Blood samples for the assays of plasma amino acids and platelet $\left[{ }^{3} \mathrm{H}\right]$-paroxetine and $\left[{ }^{3} \mathrm{H}\right]$-rauwolscine binding assays were collected at 7:45 A.M. ( $\pm 15 \mathrm{~min})$ after an overnight fast. All assays were done blind to the subject status. Plasma samples for the determination of the amino acids were kept at $-75^{\circ} \mathrm{C}$ until thawed for assay. The amino acids were determined by means of a highperformance liquid chromatography (HPLC) method, as described previously (Turnell and Cooper 1982; Maes et al. 1996). All blood specimens for the assay of plasma amino acids in PTSD patients and healthy volunteers were assayed in a single run with a single lot number of reagents and consumables employed by a single operator (AL). The intra-assay coefficients of variation (CV) values obtained in our laboratory are: tryptophan 3.3\%; tyrosine $3.8 \%$; valine $3.0 \%$; phenylalanine $3.2 \%$; isoleucine $3.4 \%$; and leucine $3.7 \%$. The tryptophan/valine + leucine + isoleucine + tyrosine + phenylalanine (CAA1) and the tyrosine/valine + leucine + isoleucine + tryptophan + phenylalanine (CAA2) ratios were computed and multiplied by 100 .

For platelet $\left[{ }^{3} \mathrm{H}\right]$-paroxetine and $\left[{ }^{3} \mathrm{H}\right]$-rauwolscine binding assays, $2 \times 9 \mathrm{ml}$ of blood was collected in silliconated tubes containing K-EDTA as anticoagulant. Within $60 \mathrm{~min}$, platelet-rich plasma was prepared by low-speed centrifugation for $10 \mathrm{~min}$ at $1500 \mathrm{rpm}(750 \mathrm{~g})$. Platelets were isolated in four centrifugation runs, pooled, counted, and washed in $8 \mathrm{ml}$ buffer A (Tris 50 $\mathrm{mm}, \mathrm{NaCl} 150 \mathrm{~mm}$, EDTA $20 \mathrm{~mm}, \mathrm{pH}$ 7.5). Platelets were counted by means of a Coulter STKS fully automated total blood cell counter. The final pellet was disrupted with and frozen in $2 \mathrm{ml}$ ice-cold buffer B (Tris 5 $\mathrm{mm}$, EDTA $5 \mathrm{~mm}, \mathrm{pH}$ 7.5). Samples were frozen at $-80^{\circ} \mathrm{C}$ until thawed for determination of binding assays. After thawing and adding $6 \mathrm{ml}$ buffer B, the platelet membranes were centrifuged twice in a Beckman PG centrifuge at $18,000 \mathrm{rpm}(39,000 \mathrm{~g})$ and twice disrupted using an ultraturrax homogenizer. The final membrane pellet was suspended in $0.8 \mathrm{ml}$ buffer $\mathrm{C}$ (glycylglycine $25 \mathrm{~mm}, \mathrm{pH} 7.6$ ), resulting in a final concentration of $4,000 \times 10 \mathrm{E} 6 / \mathrm{ml}$.

For the $\left[{ }^{3} \mathrm{H}\right]$-paroxetine binding assays, incubation mixtures consisted of $50 \mu \mathrm{l}$ platelet membrane suspension, $400 \mu \mathrm{l}$ buffer D (Tris $\mathrm{HCl} 50 \mathrm{~mm}, \mathrm{NaCl} 120 \mathrm{~mm}$, $\mathrm{KCl} 5 \mathrm{~mm}), 25 \mu \mathrm{L}\left[{ }^{3} \mathrm{H}\right]$-paroxetine at final concentrations between 0.02 and $0.8 \mathrm{~nm}$, and $25 \mu \mathrm{l}$ ethanol $10 \%$ or $25 \mu \mathrm{l}$ imipramine (diluted in ethanol $10 \%$, in a final concentration of $10 \mu \mathrm{m}$ in incubation mixture; $1,000 \times$ excess of $\left[{ }^{3} \mathrm{H}\right]$-paroxetine). Specific binding (as a percentage of total binding) was $73 \pm 5 \%$. After incubation for 120 min at $25^{\circ} \mathrm{C}$, samples were rapidly filtered through Whatman GF/B glass fiber filters under vacuum and rinsed twice with $4 \mathrm{ml}$ ice-cold buffer. We used a 40-well filtration manifold. Filters were placed in vials with $2 \mathrm{ml}$ scintillation fluid (Packard Ultima-Gold) and radioactivity was counted after $12 \mathrm{~h}$ of incubation in a Packard 460 scintillation counter. For the $\left[{ }^{3} \mathrm{H}\right]$-rauwolscine binding assays, incubation mixtures, consisted of $50 \mu \mathrm{l}$ platelet suspension, $50 \mu \mathrm{l}^{3}[\mathrm{H}]$-rauwolscine at final concentrations between 0.1 and $4.0 \mathrm{~nm}$ and $400 \mu \mathrm{l}$ buffer C. Specific binding was defined as radioactivity displaced by $10 \mu \mathrm{m}$ idazoxan. Specific binding was 80 to $90 \%$. The solution was incubated for $60 \mathrm{~min}$ at $25^{\circ} \mathrm{C}$. The samples were rapidly filtered through Whatman GF/B glass fiber filters under vacuum and rinsed twice with $4 \mathrm{ml}$ ice-cold buffer E (Tris $50 \mathrm{~mm}$, pH 7.4). Filters were placed in vials with $2 \mathrm{ml}$ scintillation cocktail 
(Packard Ultima-Gold). Radioactivity was counted after $16 \mathrm{~h}$ in a Packard 460 scintillation counter. Data were analyzed using computerized curve fitting; that is, LIGAND. $\mathrm{B}_{\max }$, and $\mathrm{Kd}$ values were derived from the calculated curves. $B_{\max }$ was expressed as fmoles/10E6 platelets. Blood specimens for the assay of platelet $\left[{ }^{3} \mathrm{H}\right]$-paroxetine and $\left[{ }^{3} \mathrm{H}\right]$-rauwolscine binding characteristics were carried out in three assays on 3 different days with a single lot number of reagents and consumables employed by a single operator (LD). To minimize the interassay analytical variability, we analyzed four samples of PTSD patients and four age-sex matched controls in each of the three assays and minimized possible effects of interassay variability on our results by means of regression analysis.

Severity of PTSD was assessed as described previously (Maes et al. 1998a; 1998b). In brief, a factor analysis (principal component method) was performed on all CIDI items in 185 victims of the above traumatic events. The factor scores on the first two varimax-rotated factors were used as measures for the severity of two different dimensions. The first factor, "depression-avoidance (DAV) dimension," contains the following items: restricted range of affect; markedly diminished interest; feelings of detachment; sense of a foreshortened future; inability to recall an important aspect of the trauma; acting or feeling as if the traumatic event is recurring; and effects to avoid activities, places, or people that arouse recollections of the trauma. The second factor, "arousal-anxiety (AA) dimension," contains the following items: physiological symptoms of anxiety; sleep disorders; recurrent distressing dreams; recurrent and intrusive distressing recollections of the event; effects to avoid thoughts, feelings, or conversations associated with the trauma; hypervigilance; intense physiological distress at exposure to cues that symbolize the traumatic event; exaggerated startle response.

\section{STATISTICS}

The independence between classification systems was checked with the analysis of contingence ( $\chi^{2}$ test). Group mean differences were checked by means of analysis of variance (ANOVA) or analysis of covariance (ANCOVA). Multiple post hoc differences between group means were checked with Fisher's least significant difference (LSD). Relationships between variables were assessed with Pearson's product-moment correlation coefficients and through multiple regression analyses. Normality of distribution was assessed with the Kolmogorov-Smirnov test. Transformations were used to reach normality of distribution or to adjust for heterogeneity of variance between study groups; that is, platelet $\left[{ }^{3} \mathrm{H}\right]$-paroxetine and $\left[{ }^{3} \mathrm{H}\right]$-rauwolscine binding values were processed after square root transformation.

\section{RESULTS}

\section{Demographic data}

In study group 1 , there were no significant differences in age $(\mathrm{F}=0.4, \mathrm{df}=1 / 43, p=.3)$ or gender $\left(\chi^{2}=\right.$ $1.3, \mathrm{df}=1, p=.2$ ) between patients with PTSD (mean age $=47.1 \pm 9.3$ years; $\mathrm{M} / \mathrm{F}$ ratio $=4 / 9$ ) and healthy volunteers (mean age: $45.3 \pm 7.7$ years; $\mathrm{M} / \mathrm{F}$ ratio $=$ $5 / 27)$. In study group 2 , there were no significant differences in age $(\mathrm{F}=0.5, \mathrm{df}=1 / 22, p=.5)$ or gender $\left(\chi^{2}=\right.$ $0.0, \mathrm{df}=1, p=1.0$ ) between patients with PTSD (mean age $=49.1 \pm 9.0$ years; $\mathrm{M} / \mathrm{F}$ ratio $=4 / 8)$ and healthy volunteers (mean age $=46.1 \pm 10.8$ years; $\mathrm{M} / \mathrm{F}$ ratio $=$ $4 / 8)$. There were no significant correlations between age and plasma tryptophan $(\mathrm{r}=-0.28, p=.95)$; tyrosine $(\mathrm{r}=0.00, p=.98)$; tryptophan/CAA1 ratio $(\mathrm{r}=$ $-0.01, p=.95) ;\left[{ }^{3} \mathrm{H}\right]$-paroxetine binding $\mathrm{B}_{\max }(\mathrm{r}=0.30$, $p=.1)$ or $\mathrm{Kd}(\mathrm{r}=0.17, p=.6)$ values; and $\left[{ }^{3} \mathrm{H}\right]$-rauwolscine binding $\mathrm{B}_{\max }(\mathrm{r}=-0.22, p=.3)$ or $\mathrm{Kd}(\mathrm{r}=0.30, p=$ .2) values. There was a significant and positive correlation between age and the tyrosine/CAA2 ratio $(r=0.36$, $p=.01$ ) (all results of intraclass correlations, pooled over the study groups of normal controls and PTSD patients). ANOVAs, factorial design with gender as second factor, showed no significant differences between males and females in plasma tryptophan $(\mathrm{F}=2.4 \mathrm{df}=$ $1 / 41, p=.1)$; tryptophan/CAA1 $(\mathrm{F}=3.7, \mathrm{df}=1 / 41$, $p=.06)$; tyrosine/CAA2 ( $\mathrm{F}=0.7, \mathrm{df}=1 / 41, p=.6)$; $\left[{ }^{3} \mathrm{H}\right]$-paroxetine binding $\mathrm{B}_{\max }(\mathrm{F}=1.0, \mathrm{df}=1 / 20, p=.3)$ or $\mathrm{Kd}(\mathrm{F}=0.0, \mathrm{df}=1 / 20, p=.8)$ values; and $\left[{ }^{3} \mathrm{H}\right]-\mathrm{rau}-$ wolscine binding $\mathrm{B}_{\max }(\mathrm{F}=1.3, \mathrm{df}=1 / 20, p=.3)$ or $\mathrm{Kd}$ $(\mathrm{F}=0.0, \mathrm{df}=1 / 20, p=.9)$ values. Tyrosine was significantly higher in males (mean $=70 \pm 8 \mu \mathrm{mol} / \mathrm{l}$ ) than in females (mean $=57 \pm 11 \mu \mathrm{mol} / \mathrm{l})(\mathrm{F}=6.3, \mathrm{df}=1 / 41$, $p=.01)$. There were no significant differences in the $\left[{ }^{3} \mathrm{H}\right]$-paroxetine binding $\mathrm{B}_{\max }$ values $(\mathrm{F}=2.7, \mathrm{df}=2 / 21$, $p=.09$ ) between the three assays. There were significant differences in $\left[{ }^{3} \mathrm{H}\right]$-paroxetine binding $\mathrm{Kd}(\mathrm{F}=4.4$, $\mathrm{df}=2 / 21, p=.02) ;\left[{ }^{3} \mathrm{H}\right]$-rauwolscine binding $\mathrm{B}_{\max }(\mathrm{F}=$ $4.5, \mathrm{df}=2 / 21, p=.02)$ and $\mathrm{Kd}(\mathrm{F}=5.6, \mathrm{df}=2 / 21, p=$ .01) values between the three assays. In any case, we have adjusted subsequent statistical analyses for possible age and gender effects and analytical interassay variability by entering age, sex, and the three analytical assays (entered as two dummy variables) as covariates in regression analyses. At the time of blood sampling, seven patients suffered from PTSD without MD and six from PTSD with MD. The mean HDRS ( \pm SD) score of patients with co-morbid depression and PTSD (19.2 \pm 3.4) was significantly higher than that of patients with PTSD only $(7.3 \pm 2.2)(\mathrm{F}=51, \mathrm{df}=1 / 10, p=.0001)$.

\section{Biological markers and PTSD}

Table 1 shows that plasma tyrosine and the tyrosine/ CAA2 ratio were significantly higher in PTSD subjects 
than in normal volunteers. ANCOVAs performed on PTSD patients divided into those with and without MD, showed that plasma tyrosine and the tyrosine/ CAA2 ratio were significantly higher in PTSD patients with MD than in normal volunteers and PTSD patients without MD. There were no significant differences in plasma tryptophan, tryptophan/CAA1 ratio, CAA1 or CAA2 between PTSD patients and healthy volunteers.

Figure 1 shows that the $\left[{ }^{3} \mathrm{H}\right]$-paroxetine binding $\mathrm{Kd}$ values were significantly higher $(\mathrm{F}=8.2, \mathrm{df}=1 / 18, p=$ .009 ) in the PTSD patients (mean $=0.048 \pm 0.016 \mathrm{~nm}$ ), irrespective of the presence of $\mathrm{MD}$, than in healthy volunteers $($ mean $=0.032 \pm 0.012 \mathrm{~nm}$ ). There were no significant differences between PTSD patients with and without MD. Figure 2 shows that the $\left[{ }^{3} \mathrm{H}\right]$-rauwolscine binding $\mathrm{Kd}$ values were significantly higher $(\mathrm{F}=5.0, \mathrm{df}=$ $1 / 18, p=.04)$ in PTSD patients (mean $=0.187 \pm 0.090 \mathrm{~nm})$ than in normal volunteers (mean $=0.138 \pm 0.057 \mathrm{~nm}$ ). PTSD patients with MD (mean $=0.234 \pm 0.106 \mathrm{~nm})$ had significantly higher $(\mathrm{F}=4.4, \mathrm{df}=2 / 17, p=.03$ ) $\left[{ }^{3} \mathrm{H}\right]$-rauwolscine binding $\mathrm{Kd}$ values than normal volunteers and PTSD patients without MD (mean $=0.140 \pm$ $0.036 \mathrm{~nm})$. There were no significant differences $(\mathrm{F}=0.9$, $\mathrm{df}=1 / 18, p=.6)$ in $\left[{ }^{3} \mathrm{H}\right]$-paroxetine binding $\mathrm{B}_{\max }$ values between PTSD patients $\left(\right.$ mean $=0.372 \pm 0.181 \mathrm{fmoles} / 10^{6}$ platelets) and healthy volunteers (mean $=0.302 \pm 0.090$ fmoles $/ 10^{6}$ platelets). There were no significant differences $(\mathrm{F}=1.8, \mathrm{df}=1 / 18, p=.6)$ in $\left[{ }^{3} \mathrm{H}\right]$-rauwolscine binding $\mathrm{B}_{\max }$ values between PTSD patients (mean $=0.113 \pm$ $0.050 \mathrm{fmoles} / 10^{6}$ platelets) and healthy volunteers (mean = $0.092 \pm 0.030 \mathrm{fmoles} / 10^{6}$ platelets) (all results of ANCOVAs with the analytical assays and/or age and gender as covariates; and of LSD performed after ANCOVAs).

To confirm the above results in patients with DSMIII-R diagnosis of PTSD only, we performed additional
ANCOVAS on the study groups of normal volunteers and the PTSD patients classified according to DSM-III-R criteria. Serum tyrosine was significantly higher $(\mathrm{F}=$ 9.7, $\mathrm{df}=1 / 37, p=.004)$ in PTSD patients with a DSMIII-R PTSD diagnosis (mean $=69.64 \pm 9.86 \mu \mathrm{mol} / \mathrm{l}$ ) than in healthy volunteers $($ mean $=55.94 \pm 10.70 \mu \mathrm{mol} / \mathrm{l}$ ). The tyrosine/CAA2 ratio $(\times 100)$ was significantly greater $(\mathrm{F}=6.6 \mathrm{df}=1 / 37, p=.01)$ in PTSD patients with a DSM-III-R PTSD diagnosis $($ mean $=12.43 \pm 1.99)$ than in healthy volunteers (mean $=10.91 \pm 1.42$ ). $\left[{ }^{3} \mathrm{H}\right]$-paroxetine binding $\mathrm{Kd}$ values $(\mathrm{F}=6.3, \mathrm{df}=1 / 14$, $p=.02$ ) were significantly higher in the PTSD patients with a DSM-III-R PTSD diagnosis (mean $=0.051 \pm$ $0.018 \mathrm{~nm}$ ) than in normal volunteers (mean $=0.032 \pm$ $0.012 \mathrm{~nm}) .\left[{ }^{3} \mathrm{H}\right]$-rauwolscine binding $\mathrm{Kd}$ values $(\mathrm{F}=5.3$, $\mathrm{df}=1 / 15, p=.03$ ) were significantly higher in the PTSD patients with a DSM-III-R PTSD diagnosis (mean = $0.194 \pm 0.112 \mathrm{~nm}$ ) than in normal volunteers (mean $=$ $0.138 \pm 0.057 \mathrm{~nm}$.

There was a significant and positive relationship between $\left[{ }^{3} \mathrm{H}\right]$-paroxetine binding $\mathrm{Kd}$ values and the DAV $(\mathrm{F}=8.1, p=.02)$ and AA ( $\mathrm{F}=6.2, p=.04)$ factor scores. There was a trend toward a positive relationship between $\left[{ }^{3} \mathrm{H}\right]$-rauwolscine binding $\mathrm{Kd}$ and the DAV ( $\mathrm{F}=$ $4.5, p=.07)$ and AA $(\mathrm{F}=2.7, p=.1)$ scores. There were no significant relationships between plasma tyrosine, the tyrosine /CAA2 ratio, plasma tryptophan, the tryptophan/CAA1 ratio, or $\left[{ }^{3} \mathrm{H}\right]$-rauwolscine binding $\mathrm{B}_{\max }$ values and the AA or DAV scores (all results of partial correlation correlations with the three analytical assays and/or age and sex as covariates). There was a positive and significant correlation between the HDRS score and the tyrosine/CAA2 ratio $(\mathrm{r}=0.61, p=.03)$ and a trend toward a significant correlation with $\left[{ }^{3} \mathrm{H}\right]$-rauwolscine binding $\mathrm{Kd}$ values $(\mathrm{r}=0.45, p=.1)$

Table 1. Measurements of Plasma Availability of Tryptophan and Tyrosine in Healthy Volunteers (HV) and Patients with Post-Traumatic Stress Disorder (PTSD), Subdivided into These With and Without Major Depression (MD)

\begin{tabular}{lcccccc}
\hline Groups & $\begin{array}{c}\text { Tryptophan } \\
\mu \mathbf{m o l} / \mathbf{l}\end{array}$ & $\begin{array}{c}\text { CAA1 } \\
\mathbf{m} \mathbf{m o l} / \mathbf{1}\end{array}$ & $\begin{array}{c}\text { Tryptophan/CAA1 } \\
\text { ratio } \times \mathbf{1 0 0}\end{array}$ & $\begin{array}{c}\text { Tyrosine } \\
\mu \mathbf{m o l} / \mathbf{1}\end{array}$ & $\begin{array}{c}\text { CAA2 } \\
\mu \mathbf{m o l} / \mathbf{1}\end{array}$ & $\begin{array}{c}\text { Tyrosine/CAA2 } \\
\times \mathbf{1 0 0}\end{array}$ \\
\hline HV & $58.3(12.1)$ & $520(105)$ & $11.34(1.60)$ & $55.9(10.7)$ & $522(107)$ & $10.91(1.42)$ \\
PTSD (all) & $61.4(11.2)$ & $555(66)$ & $11.11(2.02)$ & $68.9(9.8)$ & $548(67)$ & $12.69(2.06)$ \\
PTSD -MD & $58.1(10.6)$ & $567(69)$ & $10.24(1.34)$ & $65.9(6.5)$ & $559(73)$ & $11.90(1.57)$ \\
PTSD + MD & $65.1(11.6)$ & $542(66)$ & $12.12(2.32)$ & $72.4(12.3)^{a}$ & $534(63)$ & $13.62(2.31)^{a}$ \\
$F^{*}(\mathrm{df})$ & $0.5(1 / 41)$ & $0.8(1 / 41)$ & $0.00(1 / 41)$ & $12.0(1 / 41)$ & $0.3(1 / 41)$ & $10.9(1 / 41)$ \\
$p$ & 0.5 & 0.6 & 0.9 & 0.002 & 0.6 & 0.002 \\
$F^{* *}(\mathrm{df})$ & $2.1(2 / 40)$ & $0.6(2 / 40)$ & $1.6(2 / 40)$ & $8.0(2 / 40)$ & $0.4(2 / 40)$ & $6.8(2 / 40)$ \\
$p$ & 0.1 & 0.6 & 0.2 & 0.001 & 0.7 & 0.003 \\
\hline
\end{tabular}

All results are shown as mean $( \pm \mathrm{SD})$.

CAA1: sum of tyrosine, phenylalanine, valine, leucine, and isoleucine.

CAA2: sum of tryptophan, phenylalanine, valine, leucine, and isoleucine.

$\mathrm{F}^{*}$ : All results of ANCOVAs with age and gender as covariates, and HV and PTSD as groups.

$\mathrm{F}^{* *}$ : All results of ANCOVAs with age and gender as covariates, and HV, PTSD - MD, and PTSD + MD as groups.

aSignificantly different from HV and PTSD-MD (results of Fisher's LSD at $p=.05$, performed after ANCOVAs). 


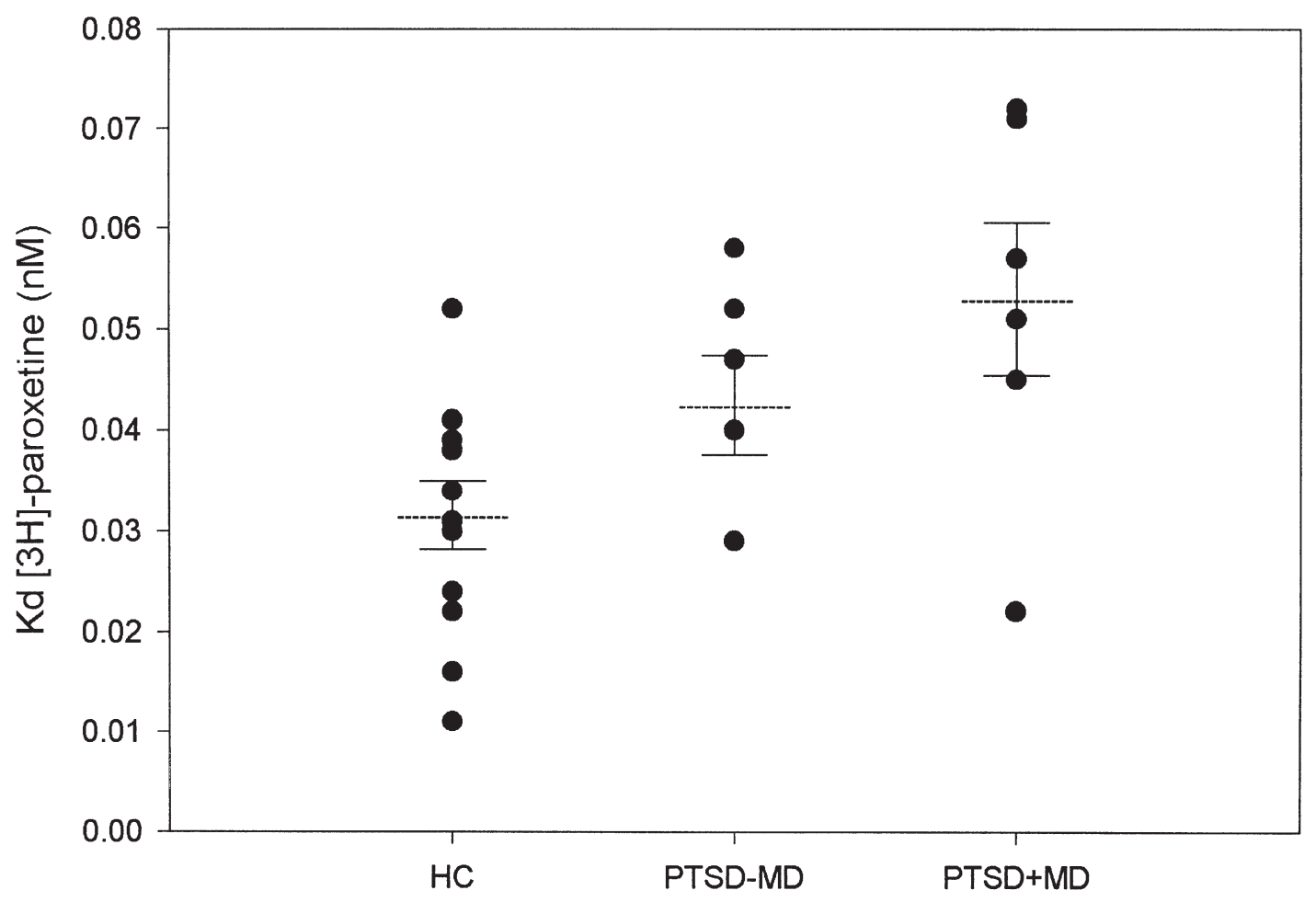

Figure 1. $\left[{ }^{3} \mathrm{H}\right]$-paroxetine binding $\mathrm{Kd}$ values in healthy volunteers (HV), and patients with post-traumatic stress disorder (PTSD) with (PTSD + MD) and without (PTSD-MD) major depression.

\section{DISCUSSION}

This study showed that the affinity of platelet $\left[{ }^{3} \mathrm{H}\right]$-paroxetine binding sites is significantly decreased in patients with PTSD, irrespective of the presence of major depression. The significant and positive correlations between severity of PTSD, either the avoidancedepression or arousal-anxiety symptoms, may suggest that graded differences in the expression of PTSD symptoms are related to changes in the 5-HT transporter system. Arora et al. (1993) reported significantly lower $\left[{ }^{3} \mathrm{H}\right]$-paroxetine binding $\mathrm{B}_{\max }$ and $\mathrm{Kd}$ values in PTSD patients than in healthy volunteers and found a negative correlation between the $\left[{ }^{3} \mathrm{H}\right]$-paroxetine binding $\mathrm{B}_{\max }$ values and a state-dependent anxiety score. Unlike patients with PTSD, no significant alterations in platelet $\left[{ }^{3} \mathrm{H}\right]$-paroxetine binding $\mathrm{B}_{\max }$ or $\mathrm{Kd}$ values could be found in major depression (Galzin et al. 1988; Lawrence et al. 1990; D'Hondt et al. 1994). These negative findings in major depression are in agreement with our results that there were no significant differences in platelet $\left[{ }^{3} \mathrm{H}\right]$-paroxetine binding characteristics between PTSD patients with and without major depression.

A question, however, is whether peripheral findings are relevant for central serotonergic activity. Blood platelets are able to take up, store, and release 5-HT via mechanisms that are very similar to those of central 5-HT neurons (Sneddon 1969; 1973; Stahl 1977). [ $\left.{ }^{3} \mathrm{H}\right]$-paroxet- ine binds with high affinity to a specific population of binding sites located on platelets and neuronal membranes associated with 5-HT uptake mechanisms (Mellerup et al. 1983; Habert et al. 1985; Cheetham et al. 1993). It has been found that the cloned 5-HT transporter on human platelets is identical to the 5-HT transporter in human brain (Lesch et al. 1993). Finally, the findings of Fichtner et al. (1994), who found a positive response to fluoxetine pharmacotherapy in PTSD patients with lower platelet $\left[{ }^{3} \mathrm{H}\right]$-paroxetine binding characteristics, suggest that findings on platelet $\left[{ }^{3} \mathrm{H}\right]$-paroxetine binding may be relevant for central serotonergic activity. The findings above may suggest that PTSD is accompanied by defects in the peripheral and perhaps central 5-HT transporter system.

In the present study, we were unable to find any significant differences in the availability of plasma tryptophan between PTSD patients and healthy volunteers. In this respect, Mellman and Kumar (1994) were unable to find significant differences either in platelet 5-HT concentrations or in platelet 5-HT uptake ( $\mathrm{Km}$ and $\mathrm{V}_{\max }$ ) measures between PTSD patients and controls.

We found that PTSD with comorbid major depression is accompanied by alterations in the peripheral catecholaminergic system; that is, higher plasma availability of tyrosine and lower affinity of platelet $\alpha 2$-ARs. There is some evidence that stressors lead to increases in the peripheral plasma tyrosine/CAA ratio, which 


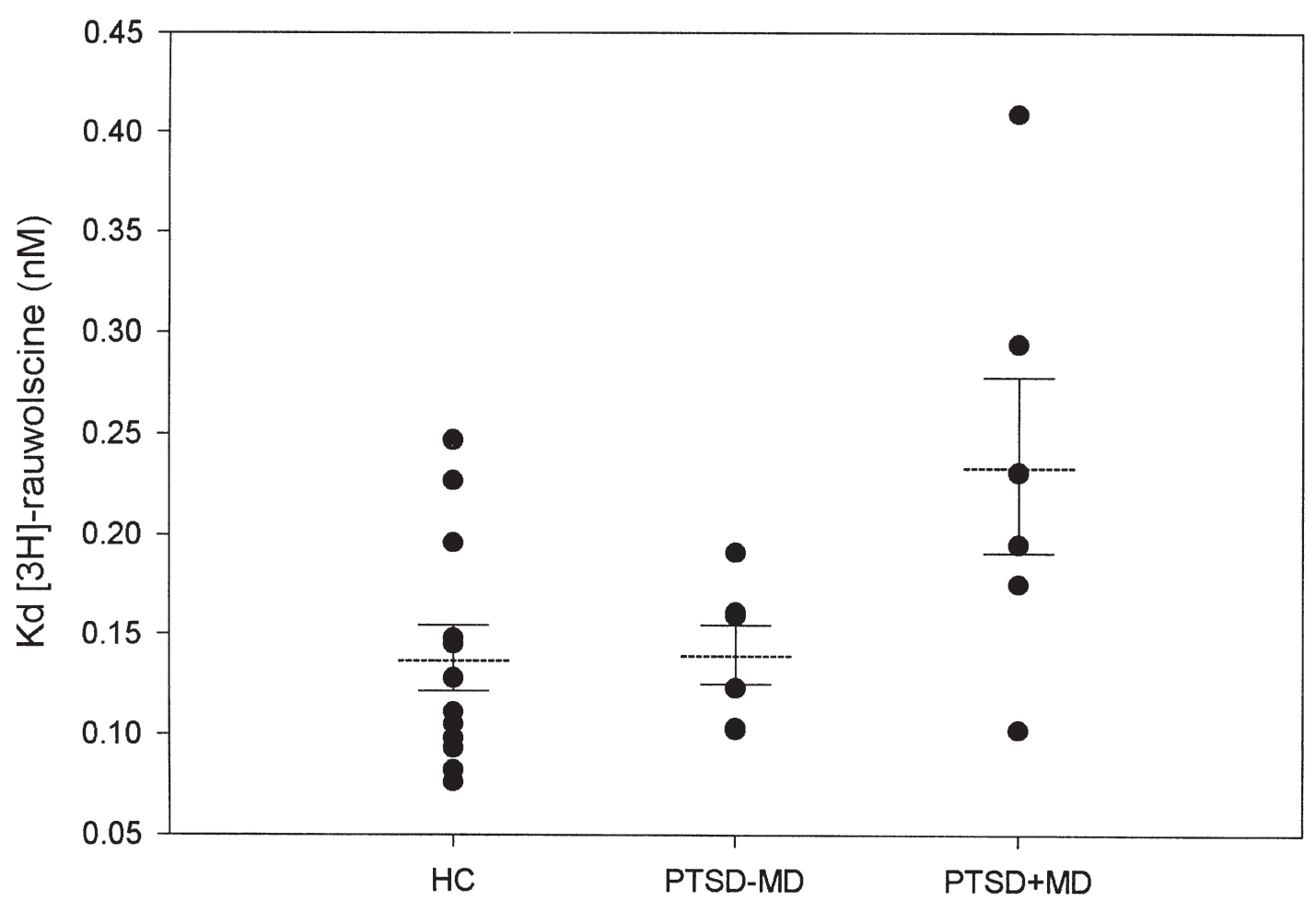

Figure 2. $\left[{ }^{3} \mathrm{H}\right]$-rauwolscine binding $\mathrm{Kd}$ values in healthy volunteers (HV), and patients with post-traumatic stress disorder (PTSD) with (PTSD + MD) and without (PTSD-MD) major depression.

corresponds to increased brain NE turnover (Rao 1987). Possible differences in diet between PTSD patients and controls are not likely to be involved in the increased tyrosine/CAA ratio found in PTSD. Although consumption of high/low protein or carbohydrate meals may acutely affect the tyrosine/CAA ratio in serum, fasting serum tyrosine concentrations (and the tyrosine/CAA ratio) did not differ significantly between humans on a control and protein-free diet over 18 days (Weller et al. 1969; Moller 1986b). A more plausible explanation for our findings revolves around the effects of NE hyperactivity in PTSD. Indeed, NE administration to rats may increase plasma tyrosine concentrations through changes in hepatic blood flow, which are probably $\alpha$-AR related (Eriksson and Carlsson 1982; Rao 1987). Interestingly, previous research has shown that supplementary dietary tyrosine may be useful therapeutically in persons chronically exposed to psychological stress (Lehnert et al. 1984; Owasoyo et al. 1992). Some, but not all, studies in depression reported a reduced availability of plasma tyrosine (review: Maes et al. 1994). These results may indicate a distinct biochemical profile with respect to plasma tyrosine in depressed patients, as compared to those with major depression and PTSD.

The findings of the present study show that the affinity of $\left[{ }^{3} \mathrm{H}\right]$-rauwolscine binding to platelets is significantly lower in patients with PTSD with a concurrent major depression than in healthy volunteers and PTSD patients without major depression. The biological significance of increased $\mathrm{Kd}$ values obtained for antagonists may be questioned. However, inhibition of $\left[{ }^{3} \mathrm{H}\right]$-dihydroergocryptine binding by antagonists showed that there was a single population of antagonist binding sites with the pharmacological characteristics of $\alpha 2$-ARs; whereas, inhibition by agonists showed two sites with different affinities (Hoffman et al. 1979). Moreover, Perry et al. (1987) reported decreased platelet $\left[{ }^{3} \mathrm{H}\right]$-rauwolscine binding $\mathrm{B}_{\max }$ values in PTSD. Adrenoceptors of the $\alpha 2 \mathrm{~A}$ subtype are expressed on platelets and presynaptically on noradrenergic neurons (Hieble et al. 1995; Limberger et al. 1995). Because platelet $\alpha 2$-ARs have very similar pharmacologic and kinetic properties as those in the brain, platelet $\alpha 2$-ARs are an adequate model for brain $\alpha 2$-ARs (Stahl 1985). Subsensitivity of central $\alpha 2$-ARs in PTSD has been suggested by Southwick et al. (1993). No significant differences in growth hormone response to desmethylimipramine administration were found between PTSD patients and normal subjects, suggesting no significant changes in central postsynaptic $\alpha 2$-ARs in PTSD (Yatham et al. 1996).

There are some reports that major depression per se is accompanied by subsensitive platelet $\alpha 2$-ARs. This evidence includes the following: (1) reduced platelet $\alpha 2-\mathrm{AR}$ responsiveness as measured by means of agonist-induced platelet aggregation and NE-induced inhibition of prostaglandine E1 (PGEI)-stimulated cyclic AMP 
(cAMP) production (Kafka et al. 1986; Kafka and Paul 1986); and (2)the density or affinity of platelet $\alpha 2$-ARs, as measured by $\left[{ }^{3} \mathrm{H}\right]$-yohimbine and $\left[{ }^{3} \mathrm{H}\right]$-rauwolscine binding to platelets, is lower in depressed patients than in healthy volunteers (Mendlewicz et al. 1989; Maes et al. 1998c). Studies in depression using partial agonists as ligands; for example clonidine, para-aminoclonidine, or UK-14304, often reported higher $\alpha 2-A R B_{\max }$ values (review: Katona et al. 1989). These compounds, however, may also bind with high affinity to catecholamineinsensitive sites; that is, imidazoline sites, which may be upregulated in major depression (Piletz and Halaris 1994). Taken together, platelet and central presynaptic autoinhibitory $\alpha 2$-ARs may be subsensitive in PTSD or a subgroup thereof; that is, those with concurrent major depression. In this respect, it has been hypothesized that hyposensitivity of presynaptic $\alpha 2$-ARs may underlie increased SNS activity (see introductory section) and exaggerated plasma NE/MHPG response to various challengers in major depression (Potter and Manji 1994, Maes et al. 1998c) and PTSD (Southwick et al. 1993; Grillon et al. 1996).

It should be underscored, however, that the subjects being studied here are not typical of the kind of PTSD patients that have been studied in other reports. Indeed, most previous studies have examined patients who are symptomatic for decades; whereas, we studied PTSD patients within 9 months after the traumatic event. Thus, differences between studies may be present as a function of time elapsed since the trauma.

In conclusion, the results suggest that serotonergic mechanisms, such as a defect in the 5-HT transporter system, may play a role in the pathophysiology of PTSD. Our results of increased plasma tyrosine availability and lowered affinity of platelet $\alpha 2$-ARs are in accordance with previous findings that PTSD is accompanied by increased SNS activity but suggest that the latter may be confined to patients with co-morbid PTSD and major depression.

\section{ACKNOWLEDGMENTS}

This research was supported in part by the Fund for Scientific Research, Vlaanderen (FWO); the Clinical Research Center for Mental Health (CRC-MH), Antwerp; and Pfizer, Belgium. The assistance of T. Creten, E. DeBoel, G. Belis, CRC-MH, Antwerp; Prof. J. Mylle, Royal Military School, Brussels; Prof. B. VanHoudenhove, M.D., KUL, Leuven; Prof. Dr. J. Leysen and W. Gommeren, the Janssen Research Foundation, Beerse, Belgium; and Assoc. Prof. C. S. North, M.D., Washington University, St. Louis, USA is greatly appreciated. The authors thank Slachtofferhulp Vlaanderen; the "Stad Antwerpen" (L. Detiege); the O.C.M.W. Antwerpen; Politie van Antwerpen and Slachtofferzorg (B. Engelen, R. VanLooveren); Slachtofferhulp, Antwerpen; the Red Cross, Vlaanderen; and the "Dienst Dringende Spoed Interventie" (D. DeBeukelaer, H. Van Gastel). The secretarial assistance of Ms M. Maes is greatly appreciated.

\section{REFERENCES}

American Psychiatric Association (APA) (1980): Diagnostic and Statistical Manual of Mental Disorders, 3rd ed, revised. Washington, DC, APA

American Psychiatric Association (APA) (1987): Diagnostic and Statistical Manual of Mental Disorders 3rd ed, revised. Washington, DC, APA

American Psychiatric Association (APA) (1994): Diagnostic and Statistical Manual of Mental Disorders, 4th ed. Washington, DC, APA

Arora RC, Fichtner CG, O'Connor F, Crayton JW (1993): Paroxetine binding in the blood platelets of post-traumatic stress disorder patients. Life Sci 53:919-928

Blanchard EB, Kolb LC, Prins A, Gates S, McCoy GC (1991): Changes in plasma norepinephrine to combat-related stimuli among Vietnam veterans with post traumatic stress disorder. J Nerv Ment Disord 179:371-373

Cheetham SC, Viggers JA, Slater NA, Heal DJ, Buckett WR (1993): $\left[{ }^{3} \mathrm{H}\right]$ Paroxetine binding in rat frontal cortex strongly correlates with $\left[{ }^{3} \mathrm{H}\right]-5-\mathrm{HT}$ uptake: Effect of administration of various antidepressant treatments. Neuropharmacol 32:737-743

D'Hondt P, Maes M, Leysen J, Gommeren W, Scharpé S, Cosyns P (1994): Binding of $\left[{ }^{3} \mathrm{H}\right]$-paroxetine to platelets of depressed patients: Seasonal differences and effects of diagnostic classification. J Affect Disord 32:27-35

Eriksson T, Carlsson A (1982): Adrenergic influence on rat plasma concentration of tyrosine and tryptophan. Life Sci 30:1465-1472

Fernstrom JD (1984): Tryptophan availability and serotonin synthesis in rat brain: Effects of experimental diabetes. In Schlossberger HG, Kochen W, Linzen B, Steinhart H (eds), Progress in Tryptophan and Serotonin Research. Berlin-New York, Walter de Gruyter, pp 161-172

Fichtner CG, Arora RC, O'Connor FL, Crayton JW (1994): Platelet paroxetine binding and fluoxetine pharmacotherapy in post-traumatic stress disorder: Preliminary observations on a possible predictor of clinical treatment response. Life Sci 54:39-44

Galzin AM, Poirier M-F, Loo H, Sechter D, Zarifian E, Langer SZ (1988): [ $\left.{ }^{3} \mathrm{H}\right]$-Paroxetine binding from healthy volunteers and depressed patients. Br J Pharmacol 93:12

Grillon C, Southwick SM, Charney DS (1996): The psychobiological basis of post-traumatic stress disorder. Mol Psychiatr 1:278-297

Habert E, Graham D, Tahraoui L, Claustre Y, Langer S (1985): Characterization of [3H]-paroxetine binding to rat cortical membranes. Eur J Pharmacol 118:107-114

Hamilton M (1960): A rating scale for depression. J Neurol Neurosurg Psychiatr 23:56-61

Hammer MB, Diamond BI (1993): Elevated plasma dopamine in post-traumatic stress disorder: A preliminary report. Biol Psychiatr 33:304-306

Hieble JP, Bondinell WE, Ruffolo RR (1995): $\alpha$ - and $\beta$-adrenoceptors: From the gene to the clinic. 1. Molecular biology and adrenoceptor classification. J Med Chem 38: 3415-3444

Hoffman BB, DeLean A, Wood CL, Schocken DD, Lefkowitz 
RJ (1979): Alpha-adrenergic subtypes: Quantitative assessment by ligand binding. Life Sci 24:1739-1746

Janca A, Üstun TB, Sartorius N (1994): New versions of World Health Organization instruments for the assessment of mental disorders. Acta Psychiatr Scand 90:73-83

Kafka MS, Paul SM (1986): Platelet $\alpha 2$-adrenergic receptors in depression. Arch Gen Psychiatr 43:91-95

Kafka MS, Nurnberger JI, Siever L, Targum S, Uhde TW, Gershon ES (1986): Alpha-2 adrenergic receptor function in patients with unipolar and bipolar affective disorders. J Affect Disord 10:163-169

Katona CLE, Theodorou AE, Davies SL, Hale AS, Kerry SM, Horton RW, Kelly JS, Paykel ES (1989): [ $\left.{ }^{3} \mathrm{H}\right]-Y o h i m b i n e$ binding to platelet $\alpha 2$-adrenoceptors in depression. J Affect Disord 17:219-228

Kosten TR, Mason JW, Giller EL, Ostroff RB, Harkness L (1987): Sustained urinary norepinephrine and epinephrine elevation in post-traumatic stress disorder. Psychoneuroendocrinology 12:13-20

Krystal JH, Kosten TR, Perry BD, Southwick SM, Mason JW, Giller EL (1989): Neurobiological aspects of PTSD: Review of clinical and preclinical studies. Behav Ther 20:177-198

Lawrence KM, De Paermentier F, Cheetham SC, Crompton MR, Katona CL, Horton RW (1990): Brain 5-HT uptake sites, labeled with $\left[{ }^{3} \mathrm{H}\right]$-paroxetine, in antidepressantfree depressed suicides. Brain Res 526:17-22

Lehnert H, Reinstein DK, Strowbridge BW, Wurtman RJ (1984): Neurochemical and behavioral consequences of acute, uncontrollable stress: Effects of dietary tyrosine. Brain Res 303:215-223

Lemieux AM, Coe CL (1995): Abuse-related post-traumatic stress disorder: Evidence for chronic neuroendocrine activation in women. Psychosom Med 57:105-115

Lesch KP, Wolozin BL, Murphy DL, Reiderer P (1993): Primary structure of the human platelet serotonin uptake site: Identity with the brain serotonin transporter. J Neurochem 60:2319-2322

Limberger N, Funk L, Trendelenburg AU, Starke K (1995): Subclassification of presynaptic $\alpha 2$-adrenoceptors: $\alpha 2$ autoreceptors in rabbit atria and kidney. NaunynSchmiedeberg's Arch Pharmacol 352:31-42

Maes M, Meltzer HY, Cosyns P, Schotte C (1994): Evidence for the existence of major depression with and without anxiety features. Psychopathology 27:1-13

Maes M, Meltzer HYM (1995): The serotonin hypothesis of major depression. In Bloom FE, Kupfer DJ (eds), Psychopharmacology, the Fourth Generation of Progress. New York, Raven Press, pp 933-944

Maes M, Wauters A, Verkerk R, Neels H, vanGastel A, Cosyns P, Scharpé S, Desnyder R (1996): Lower L-tryptophan availability in depression: A marker of a more generalized disorder in protein metabolism. Neuropsychopharmacology 15:243-251

Maes M, Delmeire L, Schotte C, Janca A (1998a): Epidemiologic and phenomenological aspects of post-traumatic stress disorder: DSM-III-R diagnosis and diagnostic criteria not validated. Psychiatr Res, in press

Maes M, Delmeire L, Creten T, Janca A (1998b): The two-factorial symptom structure of post-traumatic stress disor- der: Depression-avoidance and arousal-anxiety. Psychiatr Res, in press

Maes M, Van Gastel A, Delmeire L, Meltzer HY (1998c): Decreased platelet alpha-2 adrenoceptor density in major depression: Effects of antidepressive drugs. Biol Psychiatr, in press

Mason JW, Giller EL, Harkness L (1988): Elevation of urinary norepinephrine/cortisol ratio in post-traumatic stress disorder. J Nerv Ment Disord 176:498-502

Mellerup ET, Plenge P, Engelstoft M (1983): High affinity binding of $\left[{ }^{3} \mathrm{H}\right]$-paroxetine and $\left[{ }^{3} \mathrm{H}\right]$-imipramine to human platelet membranes. Eur J Pharmacol 96:303-309

Mellman TA, Kumar AM (1994): Platelet serotonin measures in post-traumatic stress disorder. Psychiatr Res 53:99-101

Mellman TA, Kumar A, Kulick-Bell R, Kumar M, Nolan B (1995): Nocturnal/daytime urine noradrenergic measures and sleep in combat related PTSD. Biol Psychiatr 38:174-179

Mendlewicz J, Hirsch D, Sevy S, Surmont D, Papadimitriou G, De Maertelaer V (1989): Alpha-2-adrenoceptor binding as a possible vulnerability marker for affective disorder. Neuropsychobiology 22:61-67

Moir ATB, Eccleston D (1968): The effect of precursor loading in the cerebral metabolism of 5-hydroxyindoles. J Neurochem 15:1093-1108

Moller SE (1986a): Plasma neutral amino acids and food preferences: Possible implications in normals and depressives. Biblthca Nutr Dieta 38:149-153

Moller SE (1986b): Carbohydrate/protein selection in a single meal correlated with plasma tryptophan and tyrosine ratios to neutral amino acids in fasting individuals. Physiol Beh 38:175-183

Murburg MM, McFall ME, Lewis N, Veith RC (1995): Plasma norepinephrine kinetics in patients with post-traumatic stress disorder. Biol Psychiatr 38:819-825

Owasoyo JO, Neri DF, Lamberth JG (1992): Tyrosine and its potential use as a countermeasure to performance decrement in military sustained operations. Aviat Space Environ Med 63:364-369

Perry BD, Giller EL, Southwick SM (1987): Altered platelet alpha 2-adrenergic binding sites in post-traumatic stress disorder. Am J Psychiatr 144:1511-1512

Peters L, Andrews G, Cottler LB, Chatter S, Janca A, Smeets RMW (1996): The composite International Diagnostic interview post-traumatic stress disorder module: Preliminary data. Int J Meth Psychiatr Res 6:167-174

Piletz JE, Halaris A (1994): Psychopharmacology of imidazoline and $\alpha 2$-adrenergic receptors: Implications for depression. Crit Rev Neurobiol 9:29-66

Pitman RK, Orr SP (1990): Twenty-four hour urinary cortisol and catecholamine excretion in combat-related posttraumatic stress disorder. Biol Psychiatr 27:245-247

Potter WZ, Manji HK (1994): Catecholamines in depression: An update. Clin Chem 40:279-287

Rao M-L (1987): Bioavailability of amino acids and amino acid precursors for neurotransmitter action: The role of hormones. In Huether G (ed), Amino Acid Availability and Brain Function in Health and Disease. Berlin, Springer-Verlag, pp 29-37 
Salter M, Pogson CI (1987): The importance of the liver as a regulator of amino acid supply to the brain. In Huether G (ed), Amino Acid Availability and Brain Function in Health and Disease. Berlin, Springer-Verlag, pp 21-28

Sneddon JM (1969): Sodium-dependent accumulation of 5-hydroxytryptamine by rat blood platelets. Br J Pharmacol 37:680-688

Sneddon JM (1973): Blood platelets as a model for monoamine-containing neurons. Progr Neurobiol 1:151-198

Southwick SM, Krystal JH, Morgan CA, Johnson D, Nagy LM, Nicolaou A, Heninger GR, Charney DS (1993): Abnormal noradernergic function in post-traumatic stress disorder. Arch Gen Psychiatr 50:226-274

Spitzer RL, Williams JBW, Gibbon MSW, First MB (1990): Structured Clinical Interview according to DSM-III-R. Washington, DC, American Psychiatric Press

Stahl SM (1977): The human platelet: A diagnostic and research tool for the study of biogenic amines in psychiatry and neurologic disorders. Arch Gen Psychiatr 34:509-516

Stahl SM (1985): Peripheral models for the study of neurotransmitter receptors in man. Psychopharmacol Bull 21:663-671

Starke K, Borowski E, Endo T (1975): Preferential blockade of presynaptic $\alpha$-adrenoceptors by yohimbine. Eur J Pharmacol 34:385-388

Turnell D, Cooper J (1982): Rapid assay for amino acids in serum or urine by precolumn derivatisation and reversedphase liquid chromatography. Clin Chem 28:527-531

van der Kolk BA, Dreyfuss D, Michaels M, Shera D, Berkowitz R, Fisler R, Saxe G (1994): Fluoxetine in post-traumatic stress disorder. J Clin Psychiatr 55:517-522

Voog L, Eriksson T (1992): Relationship between plasma and brain large neutral amino acids in rats fed diets with different compositions at different times of the day. J Neurochem 59:1868-1874

Weller LA, Margen S, Calloway DH (1969): Variation in fasting and postprandial amino acids of men fed adequate or protein-free diets. Am J Clin Nutr 22:1577-1583

Yatham LN, Sacamano J, Kusumakar V (1996): Assessment of noradrenergic functioning in patients with noncombat-related post-traumatic stress disorder: A study with desmethylimipramine and orthostatic challenges. Psychiatr Res 63:1-6

Yehuda R, Southwick S, Giller EL, Ma X, Mason JW (1992): Urinary catecholamine excretion and severity of PTSD symptoms in Vietnam combat veterans. J Nerv Ment Disord 180:321-325 